\title{
Pre- and postoperative refraction after cataract extraction with implantation of standard power IOL
}

\author{
THOMAS OLSEN \\ From the Department of Ophthalmology, University of Aarhus, Aarhus Kommunehospital, DK-8000 \\ Aarhus C, Denmark
}

SUMmARY The pre- and postoperative refraction results are reported in 99 patients receiving an anterior chamber lens of standard 19.0 D power after intracapsular cataract extraction. The mean refraction after the operation was $-0 \cdot 76 \mathrm{D}, \mathrm{SD} 2 \cdot 13$. Apart from eight patients with suspected lenticular myopia, $5 \%$ of the patients ended up with a refraction that differed more than $\pm 5 \mathrm{D}$ from the preoperative value. This variation was due to variation in the power of the biological lens removed at surgery, the mean value of which was $22 \cdot 8 \mathrm{D}, \mathrm{SD} 3 \cdot 3$. As a measure of the aniseikonia induced at surgery, the ocular magnification was calculated to increase $2 \cdot 7 \%, \mathrm{SD} 4 \cdot 2 \%$, as compared with the preoperative value. The variation implied that the image size increased by $10 \%$ or more in about $4 \%$ of the patients. These variations should be considered in the discussion of whether a preoperative biometry and calculation of appropriate IOL power are recommended or not.

In the era of intraocular lens (IOL) implantation it has been, and in some centres it still is, a routine procedure to implant an IOL of standard dioptric power. This paper reports on the refractive outcome in terms of changes in refraction as well as in image size induced by this procedure. In order to explain the observed variation, data were provided on the power of the biological lens removed at surgery.

\section{Materials and methods}

Ninety-nine patients, 36 men and 63 women, in the age range 56 to 89 years, mean $75 \cdot 8 \pm 7 \cdot 7( \pm S D)$ years, were investigated. They comprised an unselected sample of patients admitted for senile cataract in the period August 1984 to September 1985. In this period an indication for intracapsular extraction with IOL implantation was generally found in all cataractous patients more than 60 years old, with no complicating corneal or retinal diseases. Patients with axial myopia of more than $-8 \mathrm{D}$ were considered to be unsuitable for intracapsular extraction and were excluded from the present series. During the period of investigation it was a routine

Correspondence to Dr Thomas Olsen, Department of Ophthalmology, University of Aarhus, Aarhus Kommunehospital, DK-8000 Aarhus C, Denmark. procedure to implant an anterior chamber lens (Vision Care/3M Style 70/77) of standard 19.0 D power.

Before surgery the corneal curvature was measured in two principal meridians with a calibrated keratometer (Zeiss). The anterior chamber depth (in this paper defined as the distance from the corneal surface to the surface of the lens in situ) was measured with the Haag-Streit depth measuring attachment II, and the axial length was measured by ultrasound with the Kretz 7200 MA scanner and the immersion technique as described by Ossoinig.' The velocity of ultrasound was assumed to be $1532 \mathrm{~m} / \mathrm{s}$ in the aqueous and the vitreous, and $1641 \mathrm{~m} / \mathrm{s}$ in the lens, regardless of the cataract. ${ }^{2}$ No correction for retinal thickness was applied.

The refraction at time of surgery was recorded; in cases of myopia of recent onset the particulars of previously prescribed spectacles were obtained in order to record the basic refraction. The final refraction (spherical equivalent) was determined four to six months after surgery from the best Snellen acuity at 6 metres. All cases included in this study had a minimum visual acuity of $6 / 12$. At the same time the postoperative chamber depth and the corneal curvature were recorded.

The pre- and postoperative refraction were 
Table 1 Pre-and postoperative refractive data in 99 patients receiving an anterior chamber lens of standard $19.0 \mathrm{D}$ power. Means $\pm S D$

\begin{tabular}{|c|c|c|c|c|c|}
\hline & $\begin{array}{l}\text { Refraction } \\
\text { (D) }\end{array}$ & $\begin{array}{l}\text { Corneal power } \\
\text { (D) }\end{array}$ & $\begin{array}{l}\text { Lens power } \\
\text { (D) }\end{array}$ & $\begin{array}{l}\text { Chamber depth } \\
(\mathrm{mm})\end{array}$ & $\begin{array}{l}\text { Axial length } \\
(\mathrm{mm})\end{array}$ \\
\hline Preoperative & $-0 \cdot 01 \pm 2 \cdot 61$ & $43 \cdot 06 \pm 1 \cdot 72$ & $23.47 \pm 3.99$ & $3 \cdot 39 \pm 0.44$ & $23 \cdot 21 \pm 1 \cdot 03$ \\
\hline Postoperative & $-0 \cdot 76 \pm 2 \cdot 13$ & $42 \cdot 99 \pm 1 \cdot 76$ & $19 \cdot 00 \pm 0 \cdot 00$ & $2 \cdot 82 \pm 0 \cdot 29$ & - \\
\hline Difference & $0.75 \pm 2 \cdot 80$ & $0 \cdot 07 \pm 0.46$ & - & $0.57 \pm 0.41$ & - \\
\hline
\end{tabular}

Table 2 Pre-and postoperative data in 91 patients receiving an anterior chamber lens of standard 19.0 D power. Cases with lenticular myopia have been excluded. Means $\pm S D$

\begin{tabular}{|c|c|c|c|c|c|}
\hline & $\begin{array}{l}\text { Refraction } \\
\text { (D) }\end{array}$ & $\begin{array}{l}\text { Corneal power } \\
\text { (D) }\end{array}$ & $\begin{array}{l}\text { Lens power } \\
\text { (D) }\end{array}$ & $\begin{array}{l}\text { Chamber depth } \\
(\mathrm{mm})\end{array}$ & $\begin{array}{l}\text { Axial length } \\
(\mathrm{mm})\end{array}$ \\
\hline Preoperative & $0 \cdot 49 \pm 2 \cdot(0)$ & $43 \cdot 10 \pm 1 \cdot 64$ & $22 \cdot 75 \pm 3 \cdot 27$ & $3 \cdot 36 \pm 0.44$ & $23 \cdot 19 \pm 10 \cdot 5$ \\
\hline Postoperative & $-0.76 \pm 2 \cdot 17$ & $43 \cdot 03 \pm 1 \cdot 67$ & $19 \cdot 00 \pm 0 \cdot(00$ & $2 \cdot 81 \pm 0 \cdot 28$ & - \\
\hline Difference & $1 \cdot 26 \pm 2 \cdot 21$ & $0 \cdot 07 \pm 0.47$ & - & $0.55 \pm 0.42$ & - \\
\hline
\end{tabular}

analysed by a computer program for IOL calculation which included the calculation of the power of the biological lens in situ, the total power of the eye, and the magnification of the eye with spectacle correction for distant vision. The power of the lens in situ was calculated from assumptions on the thickness and principal planes of the biological lens as for the Gullstrand exact schematic eye. ${ }^{+}$The pre- and postoperative power of the eye with and without correction was calculated from the anterior chamber depth actually measured before and after the operation. Since the total power of the eye (with correction) is inversely related to the magnification at the retinal plane, estimates could be given of the increase in eikonia after the operation (aniseikonia of IOL eye

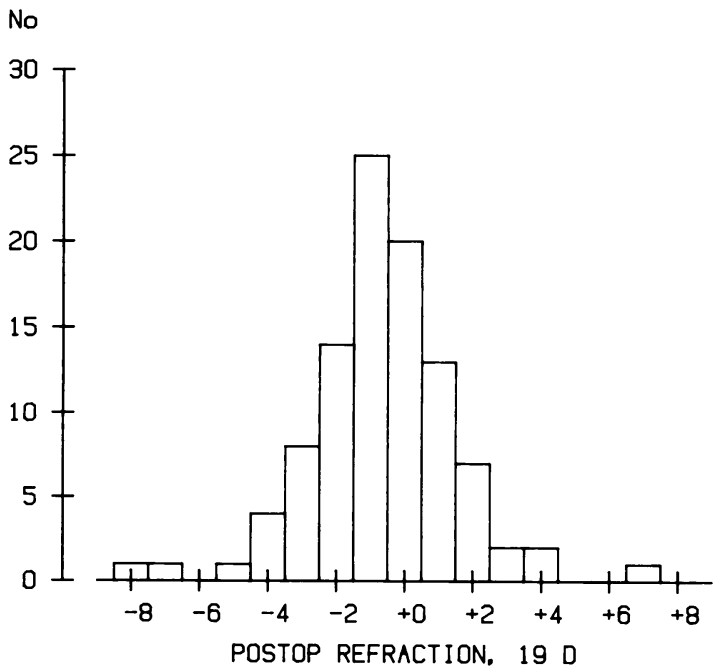

Fig. 1 The postoperative refraction in 99 patients with a standard 19.0 D anterior chamber IOL. with respect to the preoperative eye). These data were calculated as a per centage of the preoperative condition.

Statistical methods. Conventional distributional methods were used. Regression analysis was performed as linear $\mathrm{y}$ on $\mathrm{x}$ and $\mathrm{x}$ on $\mathrm{y}$ regression by the method of least squares.

\section{Results}

The pre- and postoperative data for the 99 patients receiving a standard $19.0 \mathrm{D}$ anterior chamber lens are given in Table 1 . The effect was to shift the refraction to the myopic side, the mean value being -0.76 $\mathrm{D} \pm 2 \cdot 13( \pm \mathrm{SD})$ after the operation (Fig. 1). A significant correlation was found between the preand postoperative refraction (Fig. 2). Eight patients were found to have a myopia of $-4 \mathrm{D}$ or more and at the same time a power of the biological lens of $25 \mathrm{D}$ or more; they were therefore suspected of having a lenticular myopia. After the exclusion of these cases from the analysis, the mean difference between the pre- and postoperative refraction was $1.26 \mathrm{D}( \pm 2 \cdot 21)$ (Table 2).

The mean corneal power was decreased by $0.07 \mathrm{D}$, but this was not significant $(\mathrm{p}>0 \cdot 05)$. The mean power of the biological lens removed at surgery was 23.5 D ( \pm 3.9$)$. After the exclusion of the cases with suspected lenticular myopia the mean lens power was $22 \cdot 8 \mathrm{D}( \pm 3 \cdot 3)$ (Fig. 3).

The mean power of the eye was $63.4 \mathrm{D}( \pm 3.4)$ before and $60 \cdot 3 \mathrm{D}( \pm 1 \cdot 6)$ after surgery. The magnification of the implant eye (plus spectacles) was on the average $3 \cdot 8 \%( \pm 7 \cdot 8)$ above the preoperative value. Apart from the eight cases of suspected lenticular myopia the aniseikonia amounted to $2 \cdot 7 \%( \pm 4 \cdot 2 \%)$. The variation is shown in Fig. 4. 
FINAL REFRACTION

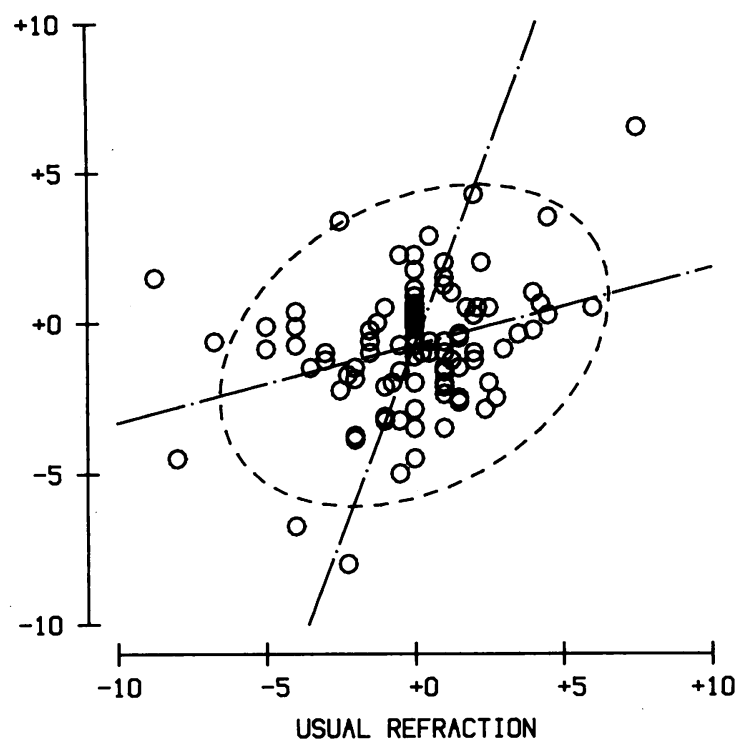

Fig. 2 Correlation between pre-and postoperative refraction in 99 patients receiving an anterior chamber lens of $19.0 \mathrm{D}$. Correlation coefficient $r=0.31(p<0.05)$. Included in figure are the regression lines $y$ on $x$ (equation $y=$ $-0 \cdot 75+0 \cdot 26 x)$, and $x$ on $y($ equation $x=0 \cdot 28+0 \cdot 39 y$ ) and the $95 \%$ tolerance ellipsis.

\section{Discussion}

The observed standard deviation of the refraction of $\pm 2.2 \mathrm{D}$ after implantation of standard power IOL is in good agreement with the results of others. ${ }^{0-10} \mathrm{On}$ the assumption of a normal distribution and a mean difference between the pre- and postoperative refraction of 1.26 (Table 2), $5 \%$ of the patients will end up with a refraction more than $\pm 5 \mathrm{D}$ from the preoperative value (apart from cases with lenticular myopia). The weak correlation between the pre- and the postoperative refraction implies that it is not possible to make a precise judgment on the appropriate IOL power on the basis of the preoperative refraction only, a view supported by the results of others. ${ }^{11-13}$

In addition to the postoperative refraction the present study provides data on the power of the biological lens, which makes it possible to discuss the cause of the refractive changes induced at surgery as well as the effects on the magnification of the eye. The available literature does not seem to provide data on the power of the biological lens in cataractous patients. However, since the work of Stenström ${ }^{14}$ and Sorsby ${ }^{15}$ a considerable variation has been known to exist in lens power and axial length in the near emmetropia region of normal subjects. Because the data of Stenström, as in the present study, were based

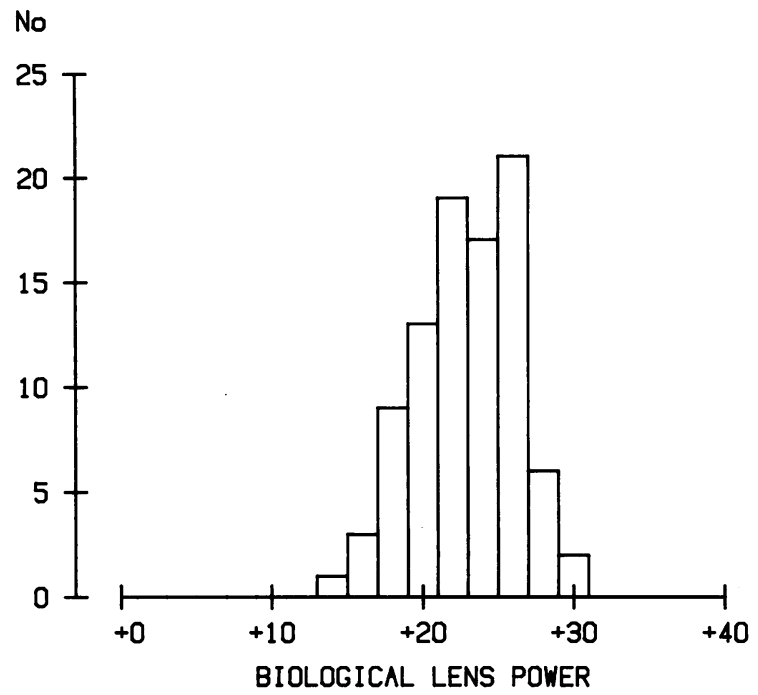

Fig. 3 The distribution of the power of the biological lens removed at cataract extraction in 91 patients in whom cases with lenticular myopia have been excluded.

on actual measurements of the axial length, a discussion of the interrelation between the data of Stenström and those found in the present study is given here.

Stenström found a mean lens power in normal young subjects of $17.4 \mathrm{D}$, calculated as the anterior

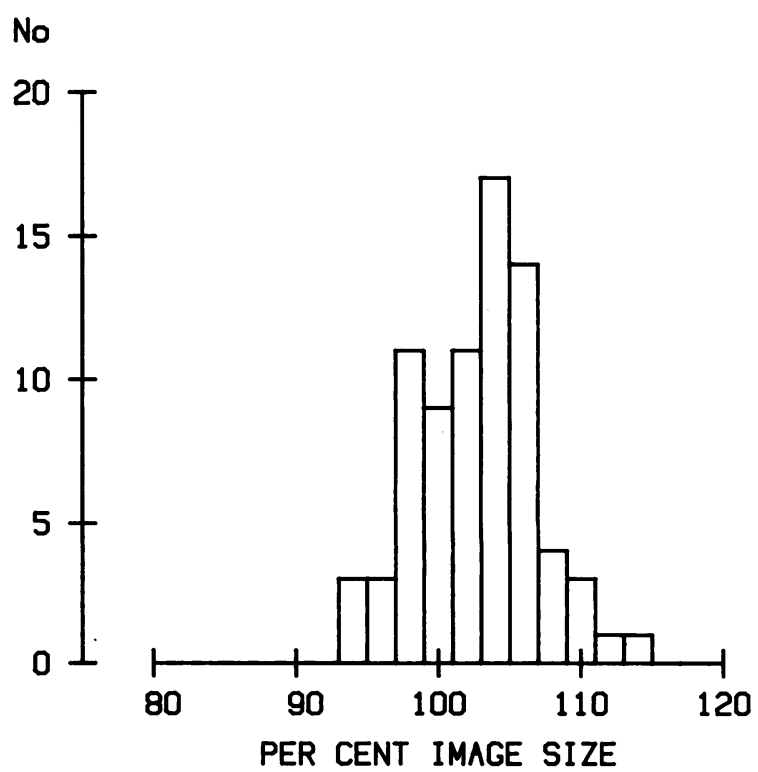

Fig. 4 The calculated aniseikonia induced at surgery in 91 patients receiving an anterior chamber lens of $19.0 \mathrm{D}$. Cases with lenticular myopia have been excluded. 
vertex power. This value corresponds to about $20.4 \mathrm{D}$ when recalculated to the second principal plane of the lens, that is, about $2 \mathrm{D}$ lower than the value found in the present study. Although efforts were made by study of the history as well as by clinical examination to exclude cases with lenticular myopia, part of the increased lens power found in the present study may be due to cataractous changes. However, other factors which need consideration are differences in measuring technique and methods of calculation. An important factor is the power of the cornea, which in Stenström's work was calculated from a fictitious refractive index of $1 \cdot 336$. The present computer program considers the cornea as a 'thick lens' of a thickness and curvature on the back surface as for the schematic eye of Gullstrand. ${ }^{4}$ This is the equivalent of using a fictitious refractive index of 1.3315 when the cornea is considered a single refracting surface. ${ }^{16}$ In this way we may explain a difference in corneal power of $0.6 \mathrm{D}$, which in turn means a difference of $0.9 \mathrm{D}$ in lens power.

Another factor is the technique of measuring the axial length. By ultrasound the 'axial length' reflects the distance from the corneal surface to the vitreoretinal surface, whereas the $x$-ray method used by Stenström measures the distance to the sensory elements of the retina. In order to correct for the thickness of the retina, a small distance must be added to the distance measured by ultrasound. But there is no general agreement on the exact value of this correction. In some theoretical formulas for IOL calculation values of $0.5 \mathrm{~mm}^{17}$ or $0.25 \mathrm{~mm}^{18}$ have been advocated on the basis of anatomical considerations. According to recent clinical studies values of $0 \cdot 15$ $\mathrm{mm}^{19}$ and $0 \cdot 14 \mathrm{~mm}^{20}$ have been suggested. Because an error of $0.1 \mathrm{~mm}$ in the axial length will cause an error in estimated biological lens power of $0.4 \mathrm{D}$, a reasonable estimate of the error between the $x$-ray and the ultrasound methods may be in the range 0.5 to $1.0 \mathrm{D}$ of the estimated biological lens power. When these considerations are taken into account, the results of the present study seem to accord well with those of Stenström.

A considerable variation was found in the difference between the calculated pre- and postoperative magnification. After omission of the cases with lenticular myopia (tending to produce falsely high values of the relative magnification), the observed variation indicated the eikonia to increase by $10 \%$ or more in $4.0 \%$ and to decrease by $10 \%$ or more in $0.1 \%$ of the patients. The average increase in magnification of $2.7 \%$ occurred despite an average shift of the refraction to the myopic side. For iris supported lenses an aniseikonia of $1-2 \%$ has been reported for IOL powers of near isometropia. ${ }^{21}$ The reason why isometropia does not produce iseikonia for anterior chamber and iris supported lenses is the anterior shift of the principal planes of the IOL as compared with the biological lens.

There is no general agreement on the amount of aniseikonia tolerated by the patient. Earlier investigations seemed to indicate that fusion can be attained with image size disparity of up to $5 \%$, but rarely with greater disparity. 223 According to more recent studies binocular function may be preserved in aphakic or pseudophakic patients with aniseikonia of up to $7 \cdot 8 \%$ or $6 \% .{ }^{24}$ Higher values may be incompatible with good stereopsis. ${ }^{24}$

Supported by the Danish Medical Research Council (grant no. 12-5628) and in part by the Institute of Experimental Clinical Research, University of Aarhus.

\section{References}

1 Ossoinig KG. Standardized echography: basic principles, clinical application and results. Int Ophthalmol Clin 1979; 19: 127-210.

2 Jansson F, Kock E. Determination of the velocity of ultrasound in the human lens and vitreous. Acta Ophthalmol (Kbh) 1962; 40: 420-33.

3 Olsen T. A theoretical approach to IOL calculation using Gaussian optics. J Cataract Refract Surg 1987; 13: 141-5.

4 Gullstrand A. Die Dioptrik des Auges. In: Helmholtz H von, ed. Handbuch der physiologischen Optik. 3rd ed. Hamburg, Leipzig: Hirgel, 1909: 226-376.

5 Armitage P. Statistical methods in medical research. London: Blackwell Scientific Publications, 1977.

6 Kraff MC, Sanders DR, Lieberman HL. Determination of intraocular lens power: a comparison with and without ultrasound. Ophthalmic Surg 1978; 9: 81-4.

7 Retzlaff J. A new intraocular lens calculation formula. Am Intraocular Implant Soc J 1980; 6: 148-52.

8 Binkhorst CD, Leonard PAM. Results in 208 irisclip pseudophakos implantations. Am J Ophthalmol 1967; 64: 947-56.

9 Hillman JS. Intraocular lens power calculation-the selection of formula. Trans Ophthalmol Soc UK 1985; 104: 693-8.

10 Thompson SM, Mohan-Roberts V. A comparison of postoperative results with and without intraocular lens power calculation. Br J Ophthalmol 1986; 70: 22-5.

11 Binkhorst RD. Pitfalls in the determination of intraocular lens power without ultrasound. Ophthalmic Surg 1976; 7: 69-73.

12 Clavenger $C E$. Clinical prediction versus ultrasound measurement of IOL power. Am Intraocular Implant Soc J 1978; 3: 222-4.

13 Saunders DR, Kraff MC. Improvement of intraocular lens power calculation using empirical data. Am Intraocular Implant Soc J 1980; 6: 263-7.

14 Stenström S. Untersuchungen über die Variation und Kovariation der optischen Elemente des menschlichen Auges. Acta Ophthalmol (Kbh) 1946: suppl 26.

15 Sorsby $A$. The functional anomalies of the eye. In: Sorsby A, ed. Modern ophthalmology. London: Butterworths, 1964; 3: 3-20.

16 Olsen $T$. On the calculation of corneal power from curvature of the cornea. BrJ Ophthalmol 1986; 70: 152-4.

17 Colenbrander MC. Calculation of the power of an irisclip lens for distant vision. Br J Ophthalmol 1973; 57: 735-40.

18 Binkhorst RD. Intraocular lens power calculation manual. A guide to the author's TI CC-40 programs. 3rd ed. New York: RD Binkhorst, 1984.

19 Binkhorst RD. The accuracy of ultrasonic measurement of the axial length of the eye. Ophthalmic Surg 1981; 12: 363-5.

20 Olsen T. Theoretical, computer assisted prediction versus SRK 
prediction of postoperative refraction after IOL implantation. J Cataract Refractive Surg 1987; 13: 146-50.

21 Hillman JS, Hawkswell A. The control of aniseikonia after intraocular lens implantation. Trans Ophthalmol Soc UK 1985; 104: $582-5$

22 Nolan J, Hawkswell A. Clinical aspects of unilateral aphakia. Trans Ophthalmol Soc UK 1974; 94: 480-6.
23 Troutman RC. Artiphakia and aniseikonia. Am J Ophthalmol 1963; 56: 602-39.

24 Huber C, Meier U, Hess F. Klinische wert der Iseikonie bei der Korrektur des aphaken Auges. Klin Monatsbl Augenheilkd 1983; 182: $379-82$.

Accepted for publication 29 January 1987. 